\title{
SHIELD EFFECT OF FUNCTIONAL INTERLINING FABRIC
}

\author{
Bosiljka Šaravanja ${ }^{1}$, Krešimir Malarić ${ }^{2}$,anja Pušić3 ${ }^{3}$ Darko Ujević ${ }^{1}$ \\ ${ }^{1}$ University of Zagreb, Faculty of Textile Technology, Department for Clothing Technology, Prilaz baruna Filipovića 28a, \\ 10000 Zagreb, Croatia, phone: 38513712 544, fax: 35813712 519, E-mail: bosiljka.saravanja@ttf.hr; darko.ujevic@ttf.hr \\ 2University of Zagreb, Faculty of Electrical Engineering and Computing, Unska 3, 10000 Zagreb, Croatia, \\ phone: 38516129 789, fax: 35816129 717,E-mail: kresimir.malaric@fer.hr \\ ${ }^{3}$ University of Zagreb, Faculty of Textile Technology, Department for Textile Chemistry \& Ecology, Savska cesta 16/N, 10000 Zagreb, Croatia, \\ phone: 38514877 354, fax: 35814877 354, E-mail: tpusic@ttf.hr \\ Corresponding author: Bosiljka Šaravanja, mag. ing. techn. text., bosiljka.saravanja@ttf.hr
}

\begin{abstract}
:
Electromagnetic interference (EMI) have become very serious in a variety of different electronic equipments, such as personal computers (frequency at several $\mathrm{GHz}$ ), mobile devices $(0.9-2.4 \mathrm{GHz}$ ) and similar. This imposes the need for setting boundaries for EM emission of electric and electronic devices in order to minimize the possibility of interference with radio and wireless communications. Functional textiles can offer protective properties against EM radiation. The aim of this study is to investigate the degree of protection against EM radiation provided by polyamide copper-coated interlining fabric before and after dry cleaning treatment. EM protection efficiency of the interlining functional fabric is explored on both sides at the frequencies of 0.9; $1.8 ; 2.1$ and $2.4 \mathrm{GHz}$. The results obtained have shown that the interlining fabric has good protective properties against EM radiation, but after dry cleaning, treatment reduction is observed. Scanning electron microscopy micrographs of the interlining surface confirms shield effect decline due to degradation and firing of the copper layers during the process of dry cleaning.
\end{abstract}

\section{Keywords:}

interlining fabric, shield effect (SE), electromagnetic interference (EMI), dry cleaning, scanning electron microscopy (SEM)

\section{Introduction}

Medical studies have reported that frequent usage of electronic and electrical devices can cause increase in stress, insomnia, headaches, cardiac arrhythmias, behavior changes, cancer, etc. [1-3]. There is a great expansion in the use of the microwave spectrum due to information technology and communication technologies development. To reduce the radiation effect, various methods have been developed including equipment, protective clothing, education and awareness of staff working under electromagnetic (EM) conditions. High electrical conductive materials are specially recommended against EM. EM protection factor is defined as the ratio between the intensity of the EM field $\left(E_{0}\right)$ measured without the material to be tested and the intensity of the EM field $\left(E_{1}\right)$ with the material placed between the source of radiation and the receiver [4]. At present, it would be of paramount importance to reduce the negative effects caused by the EM waves on humans, animals and the environment. The EM waves going through the body will start vibrating and cause the molecules to emit heat. In the same way, when the EM wave occurs in the human body it prevents DNA and RNA cells regeneration [5]. On these bases, there is a need to set EM emission boundaries of all electrical and electronic devices in order to minimize the possibility of interference with radio and wireless communications. Scientists have shown great interest in the field of textile technology for the development of textile products with electric properties against EM radiation. Textile industries around the world are trying to produce such woven, nonwoven and knitted fabrics as well as composite structures for protective applications [6-12]. The analysis of EM field by specially fabricated woven protective structures based on application of hybrid fancy yarns and their functional components in weft direction showed that electric field shielding properties of these fabrics allowed them to be used to limit exposure to electric field [9]. Construction parameters of protective woven fabrics such as warp and weft density, diameter of wires and lay-up angle also had significant effect on shielding effectiveness [11]. Knitted structures produced from a proper ferromagnetic material can also be appropriate for protection purposes against EM radiation [11]. EM shield effectiveness of the metal composite fabrics could be tailored by modification of metal grid size as well as geometry [12].

Among others, products based on textiles and composite materials have gained great attention due to diverse and wide range of applications [13]. For the EM radiation protection, electrically conductive textiles are lightweight, flexible and costeffective instead of electro-conductive metals or protective materials made of wire meshes for protection in the electrical and electronics industries [14]. Study on different knitted structures using stainless copper and produced on a flat-knitting machine, reported that samples having double metal wires have better protective properties $[15,16]$. In order to protect the human body from EM radiation, research has been carried out on woven and knitted fabrics made up of composite yarns. These yarns are composed of electrically conductive materials $(\mathrm{Cu}$, $\mathrm{Ag}, \mathrm{Ti}, \mathrm{Ni}$, etc.) wrapped in cotton or synthetic yarns $[17,18]$. 
The protective effect is defined as the ratio between the field strength at a given distance from the source without protection (shield), and the field strength with shield. Alternatively, the protective effect of the conductive barrier $(\mathrm{dB})$ is the sum of the reflection loss $(R)$, absorption loss $(A)$ and the loss of anew reflectance $(\mathrm{Rr})$. In another study, the influence of the materials, the metallic material presence, number of threads, fabric density, number of openings (apertures) and number of layers on the protective properties of the fabric against EM radiation, was examined. It was reported that the shield effect (SE) increased with the increasing number of layers, yarn count reduction (yarn becomes coarser) and the metals present in the fabric [19]. EM interference (EMI) has become very serious because of a variety of electronic equipments such as personal computers (clock frequency of $\mathrm{GHz})$, mobile devices $(0.9 \mathrm{GHz}$ $-2.4 \mathrm{GHz}$ ) and others [20].

As noted, numerous studies in EM shielding effectiveness of textiles were based on differentiation in material (composition, construction and production), methodology and wide range of frequencies in application, while the number of studies related to the textile care processes was insufficient. The aim of this paper is to study the EM protection of an interlining fabric (IF) shield, type B961 A Cu, before and after the dry cleaning treatment. This functional interlining fabric is meant to be sewn into men's jackets pockets, pants and other garments, where it can provide certain degree of protection against the harmful effects of mobile devices' radiation. The efficiency of EM protection provided by interlining polyamide (PA) fabric coated with copper, was investigated on both sides at the frequencies of: $0.9,1.8,2.1$, and $2.4 \mathrm{GHz}$.

\section{Materials and methods}

\subsection{Material textile interlining fabric}

The EM SE was tested on sewn IF, type B961 A Cu, supplied by tt. Kufner, Germany, Fig. 1. According to manufacturer's specification, the fabric is composed of $100 \%$ PA filament metallized with copper. The IF, with a surface mass of $52 \pm 5 \mathrm{~g} /$ $\mathrm{m}^{2}$, included PA filaments, in both warp and weft directions. The IF technical documentation certifies its protective properties tested according to ASTM-D-4935-89 standard within different frequency ranges, from 0.45 to $10 \mathrm{GHz}$, and from 0.45 to $2.45 \mathrm{GHz}$.

\subsection{Dry cleaning}

Despite the fact that IF label allows washing and dry cleaning, this paper deals with the dry cleaning impact on the SE properties of the fabric. The process specified in Tab. 1 was performed in a dry cleaning machine with a load of $16 \mathrm{~kg}$. For

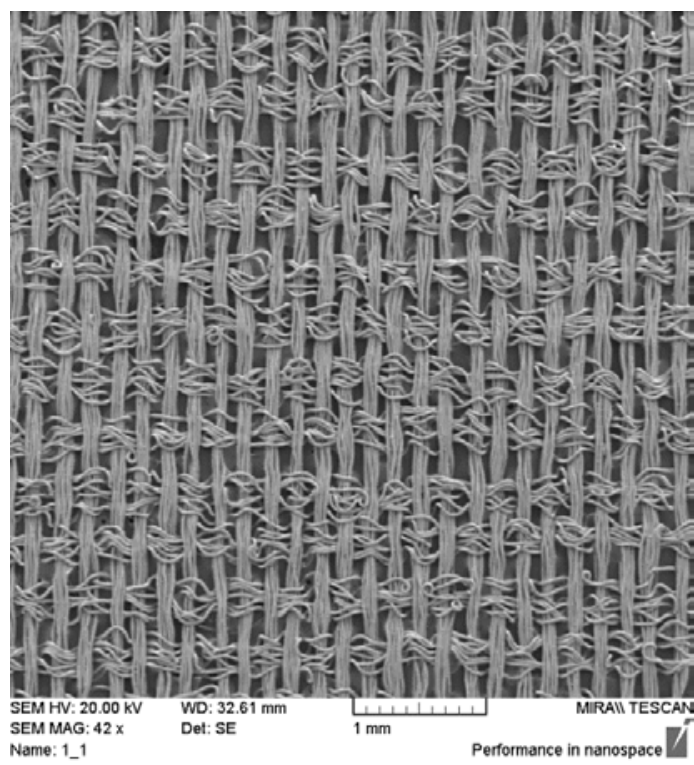

Figure 1. Scanning electron microscopy image of interlining fabric, magnification $42 x$

Table 1. Dry cleaning process

\begin{tabular}{|c|c|c|c|}
\hline Dry cleaning & $\mathbf{1}^{\text {st }}$ bath & 2 $^{\text {nd }}$ bath & Drying \\
\hline & Pre-cleaning & Cleaning & 60 \\
\hline Temperature $\left[{ }^{0} \mathrm{C}\right]$ & 20 & 20 & $30(5 / 5)$ \\
\hline Time $[\mathrm{min}]$ & 4 & 6 & - \\
\hline$\left[\mathrm{min}^{-1}\right]$ & 300 & 360 & - \\
\hline PERC [l] & 20 & 40 & - \\
\hline Detergent & Mega super star & - & - \\
\hline Bath ratio $(\mathrm{BR})$ & $1: 2$ & $1: 4$ & \\
\hline
\end{tabular}


this purpose, perchlorethylene (PERC) was used, over two baths procedure. Special dry cleaning procedure $(w=2 \%)$, included Seecapur Mega Star (Büfa, Germany), addition in the first PERC bath. This agent is formulated with new, biodegradable cationic surfactants intended for antistatic and improved cleaning effect. The IF samples with dimensions of 1 $\times 1 \mathrm{~m}$ were dry cleaned through 10 cycles.

\subsection{The electromagnetic interference}

The interaction of human body and outer EM field in today's world is inevitable because of the conditions we live in. Most people are exposed to the EM fields in a certain way through various electric or electronic devices (cellular phones, PCs, microwave ovens as well as TV or radio transmitters). EMI introduces unwanted voltages and currents into the equipment circuitry. The higher the level of voltage or current, the higher the radiated or conducted level of interference will be [21]. EM fields are used for various purposes, such as medicine, industry, communications, etc. EMI can be observed as a special kind of environmental pollution with possible health effects. Electromagnetic spectrum is a natural source used vastly in the last century, so all the new technologies are using higher and higher frequencies. Too much exposure to EM radiation can lead to serious injury, disease or even death. Prevention is thus necessary. The intensity of electric field $(E)$, which is defined by force upon a still electron, is expressed in V/m [21].

The shielding effectiveness of the protection shield SE $(\mathrm{dB})$ of the interlining fabric is calculated by equation [21]:

$$
S E=20 \log \frac{E_{1}}{E_{2}}
$$

where, $E_{1}$ is the level of the received field without shield and $E_{2}$ is the level of electric field with shield.

Measurements of the EM shielding effectiveness of the interlining fabric (B961 A Cu) on both face and reverse side were carried out in the microwave laboratory of the Department of Wireless Communications, University of Zagreb, Faculty of Electrical Engineering and Computing in Zagreb.

The measurement setup in which the measurements were conducted was set according to international standards IEESTD 299-97, MIL STD 285, and ASTM D 4935-89 [22-24].
Custom-made setup consisted of a signal generator, horn antenna (as well as a dipole antenna) and a measuring instrument, spectrum analyzer, NARDA SRM 3000 (Fig.2). The fabric was placed between the antenna and the measuring instrument.

The measurements were carried out at frequencies of $0.9,1.8$, 2.1 and $2.4 \mathrm{GHz}$, after the $1^{\text {st }}, 3^{\text {rd }}, 5^{\text {th }}, 7^{\text {th }}$ and $10^{\text {th }}$ dry cleaning cycle.

\subsection{Scanning electron microscopy}

The Tescan SEM VEGA5136 MM scanning electron microscope was used for surface examination of the IF samples before and after the dry cleaning cycles and ironing. The samples were fixed on the sample holder and sputter - coated with a palladium-gold alloy. The samples were examined using two types of signals produced by scanning electron microscopy (SEM), including secondary electrons with acceleration voltage of $20.0 \mathrm{kV}$ and magnification of 500x. SEM analyses were carried in the Department of Textile Chemistry and Ecology, University of Zagreb, Faculty of Textile Technology.

\section{Results and discussion}

Figures $3-10$ are showing the measured SE of the interlining fabric, labeled as B961 A Cu, on both sides, after the $1^{\text {st }}, 3^{\text {rd }}$, $5^{\text {th }}, 7^{\text {th }}$ and $10^{\text {th }}$ cleaning cycle with the frequencies at: $0.9 ; 1.8$; 2.1 and $2.4 \mathrm{GHz}$.

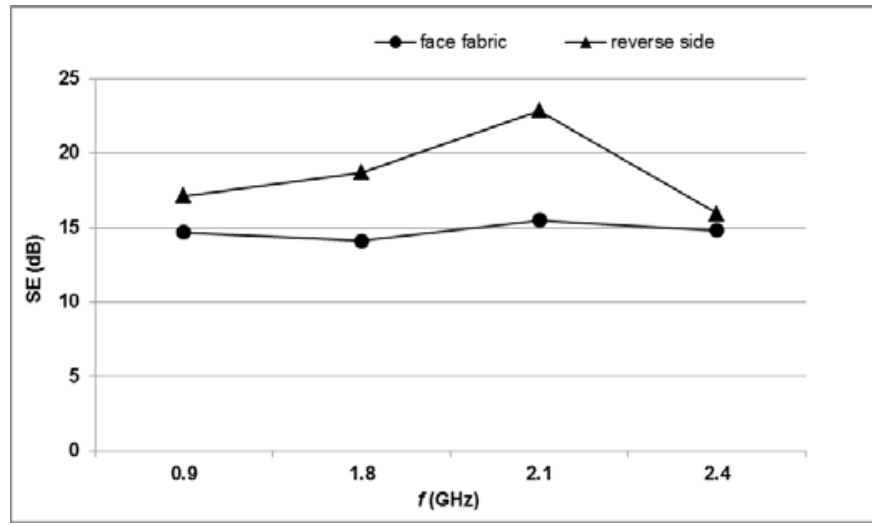

Figure 3. SE of functional IF before dry cleaning process

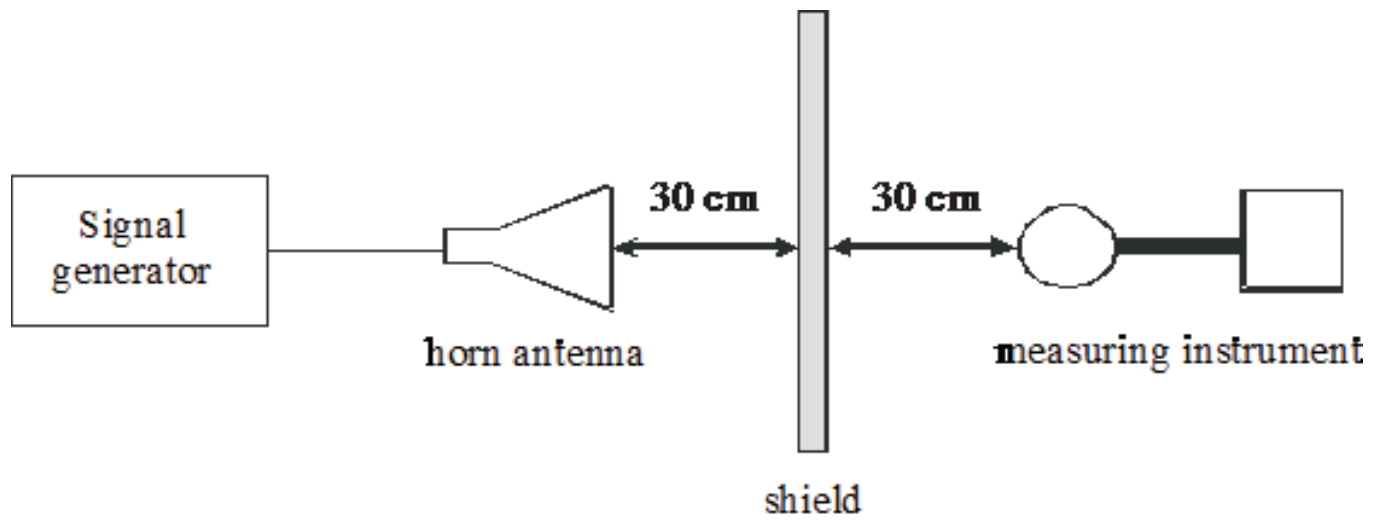

Figure 2. SE measurement setup 
Figure 3 gives the SE values of the IF face and reverse side before dry cleaning process. The SE values of the fabric face measured at 0.9 to $2.4 \mathrm{GHz}$ are almost equal and around 15 $\mathrm{dB}$. The SE values of the fabric reverse side vary in the ranges of $15.92 \mathrm{~dB}$ at the frequency of $2.4 \mathrm{GHz}$ to $22.83 \mathrm{~dB}$ at the frequency of $2.1 \mathrm{GHz}$. The latter confirms the best level of protection at almost highest frequency.

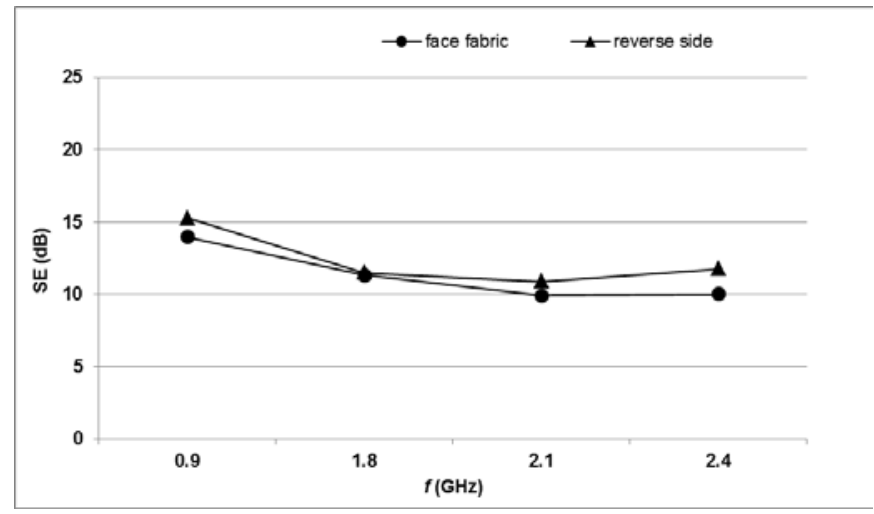

Figure 4. SE of functional IF after first dry cleaning cycle

Figure 4 gives the SE values of the IF face and reverse side after the first dry cleaning cycle in the frequency range of 0.9 to $2.4 \mathrm{GHz}$. There was less SE decline at $0.9 \mathrm{GHz}$, as given by the values of the fabric face $(13.96 \mathrm{~dB})$ and reverse side (15.29 $\mathrm{dB}$ ) compared to initial ones. At the frequency of $1.8 \mathrm{GHz}$, the SE decrease is higher, around $11 \mathrm{~dB}$, on both sides. Weak IF protection between $9.91 \mathrm{~dB}$ and $10.00 \mathrm{~dB}$ is recorded on the fabric reverse side at the highest frequencies of 2.1 and 2.4 $\mathrm{GHz}$.

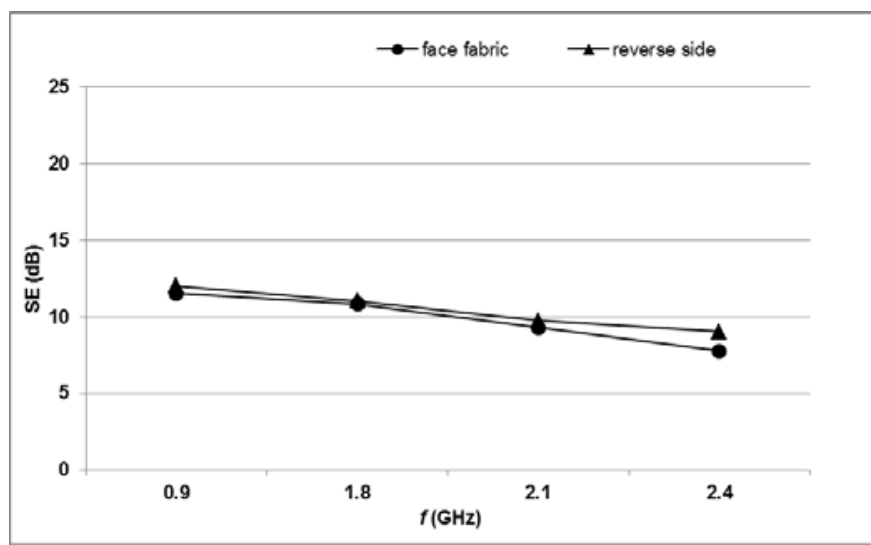

Figure 5. SE of functional IF after third dry cleaning cycles

Figure 5 gives the SE values of the IF face and reverse side after the third dry cleaning cycle. At the frequencies of $0.9,1.8$ and $2.1 \mathrm{GHz}$, the SE values on both sides are almost identical. At the frequency of $2.4 \mathrm{GHz}$, the SE of the fabric face was 7.77 and $9.01 \mathrm{~dB}$ on the reverse side of the fabric.

Figure 6 gives the SE values of the IF face and reverse side after the fifth dry cleaning cycle. The decline in SE value of the fabric face is significant at the frequencies of $1.8 \mathrm{GHz}(4.62$ $\mathrm{dB})$. At the fabric reverse side, there was proportional decrease in the SE values for all frequencies and without significant deviations.

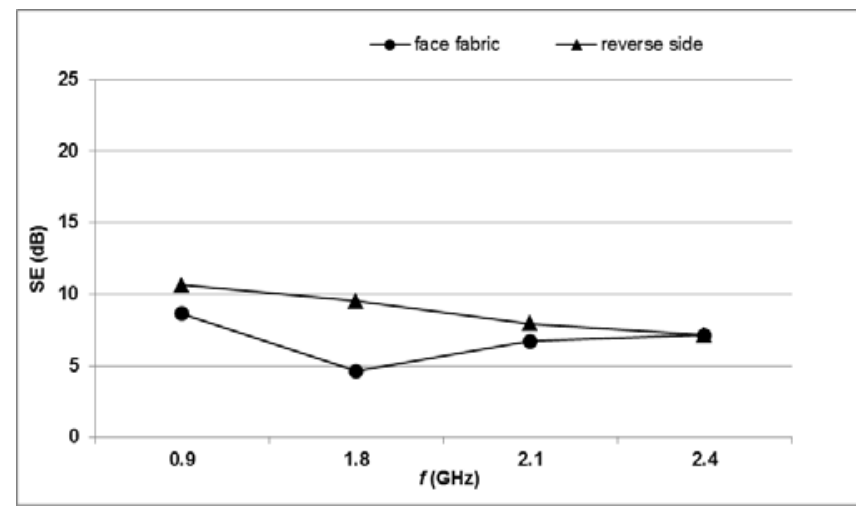

Figure 6. SE of functional IF after fifth dry cleaning cycles

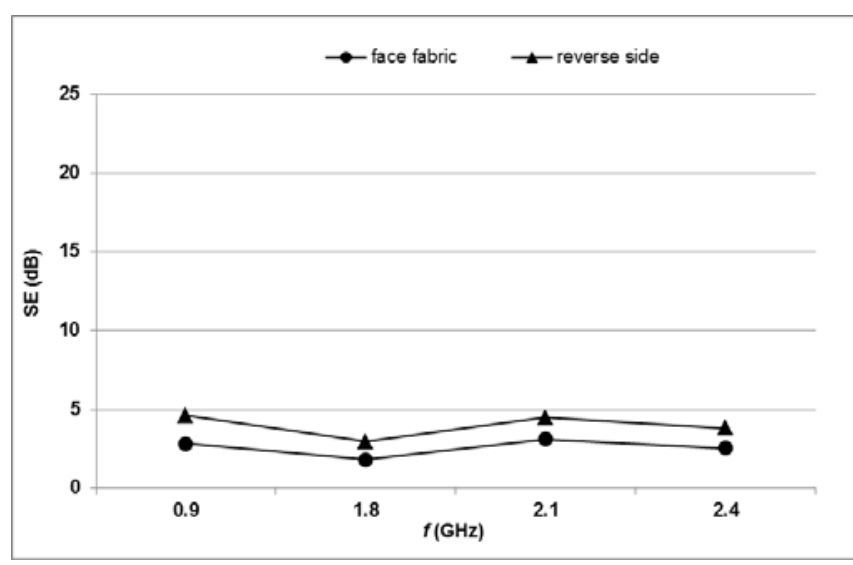

Figure 7. SE of functional IF after seventh dry cleaning cycles

Figure 7 gives the SE values of the IF face and reverse side after the seventh dry cleaning cycle. Higher SE variations were recorded at the frequencies of 1.8 and $2.4 \mathrm{GHz}$. Higher SE values of 4.6 and $4.49 \mathrm{~dB}$ were recorded for the fabric reverse side at the frequencies of 0.9 and $2.1 \mathrm{GHz}$, respectively. The protective properties of IF are decreased after the seventh cycle of dry cleaning; SE was less than $5 \mathrm{~dB}$.

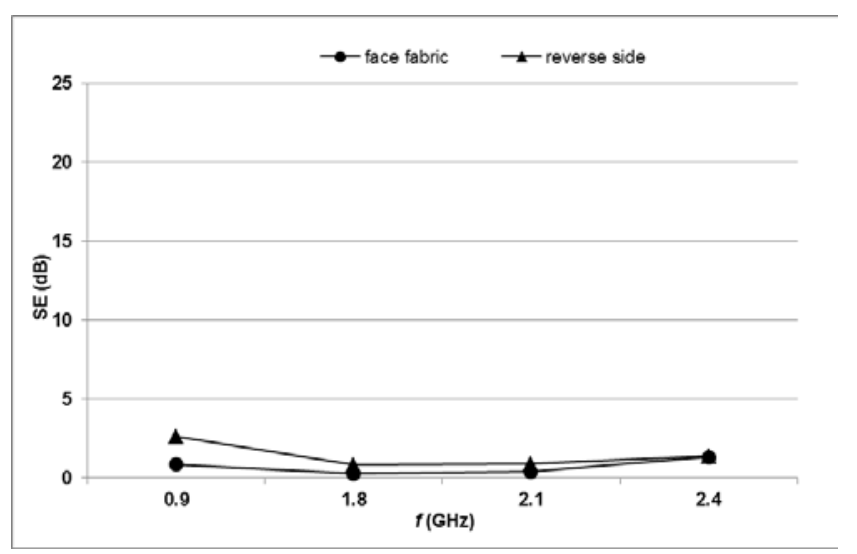

Figure 8. SE of functional IF after tenth dry cleaning cycles

Figure 8 gives the SE values of the IF face and reverse side after the tenth dry cleaning cycle. It was noticed that the SE values were almost as low as for the EM radiation to pass through entirely, thus the IF shielding was lost.

Figure 9 gives the SE values of the IF face before and after $1^{\text {st }}, 3^{\text {rd }}, 5^{\text {th }}, 7^{\text {th }}$ and $10^{\text {th }}$ dry cleaning cycle. The IF has highest protection at the frequency of $1.8 \mathrm{GHz}$ before any treatment. 
After each dry cleaning cycle, the SE decreases with the EM radiation passing through at the seventh cycle. After cycle number 10 , the SE is lower than $2 \mathrm{~dB}$ for all frequencies, resulting in the loss of fabric shielding properties.

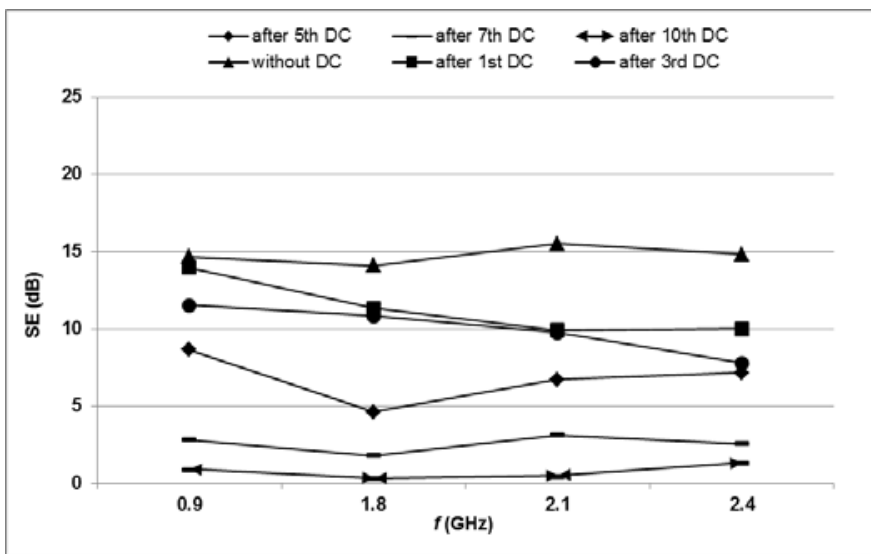

Figure 9. SE of IF face side before and after $1^{\text {st }}, 3^{\text {rd }}, 5^{\text {th }}, 7^{\text {th }}$ and $10^{\text {th }}$ dry cleaning cycles

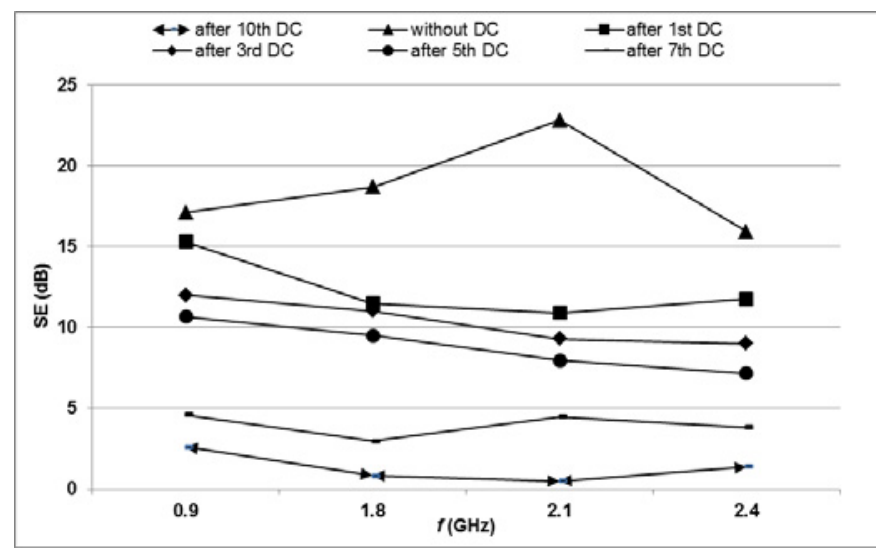

Figure 10. SE of IF reverse side before and after $1^{\text {st }}, 3^{\text {rd }}, 5^{\text {th }}, 7^{\text {th }}$ and $10^{\text {th }}$ dry cleaning cycles

Figure 10 gives the SE values of the IF reverse side before and after $1^{\text {st }}, 3^{\text {rd }}, 5^{\text {th }}, 7^{\text {th }}$ and $10^{\text {th }}$ dry cleaning cycle. It was noticed that the SE decreases as the number of cycles increases. On the fabric reverse side, SE was $17.12 \mathrm{~dB}$ before and $2.62 \mathrm{~dB}$ after the tenth dry cleaning cycle. The SE value of the fabric at the frequency of $2.1 \mathrm{GHz}$ before dry cleaning was $22.83 \mathrm{~dB}$, but this value had declined $(9.91 \mathrm{~dB})$ with the first cycle already. After the third cycle, the changes of the SE are not significant (9.28 dB), compared to cycle number seventh (4.49 dB). At the frequencies of 2.4 and $0.9 \mathrm{GHz}$, the SE decrease was uniform and opposite to SE at 1.8 and $2.1 \mathrm{GHz}$.

IF samples were treated in PERC with minimal mechanical agitation through 10 cycles, so it was interesting to study the synergy of chemical impact of organic solvent and mechanics on persistence of copper coating by SEM. Surface examination of the IF samples before and after dry cleaning was presented by SEM micrographs of the functional IF before and after dry cleaning cycles are presented in Figs.11-13.

Figure 11 presents SEM image of the initial sample of IF (before dry cleaning treatment). The PA yarns were uniformly coated with copper in warp in weft direction as presented in Fig. 11.

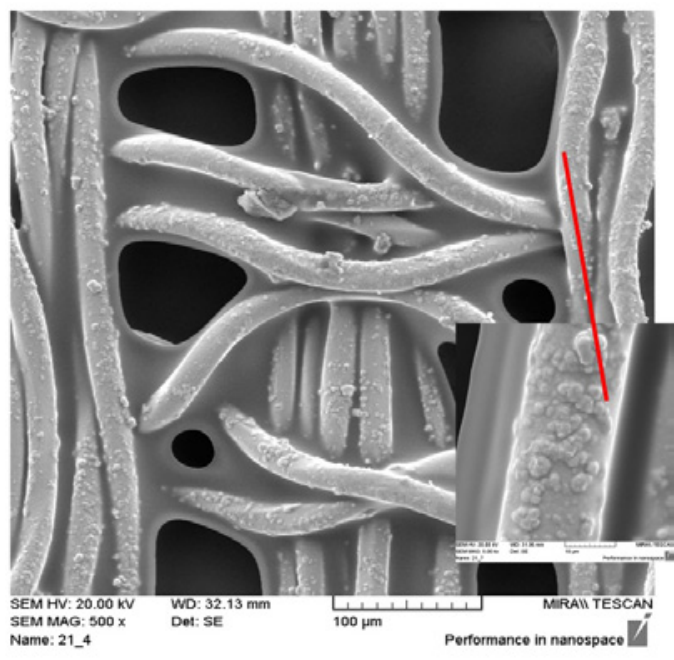

Figure 11. SEM image of the IF before dry cleaning

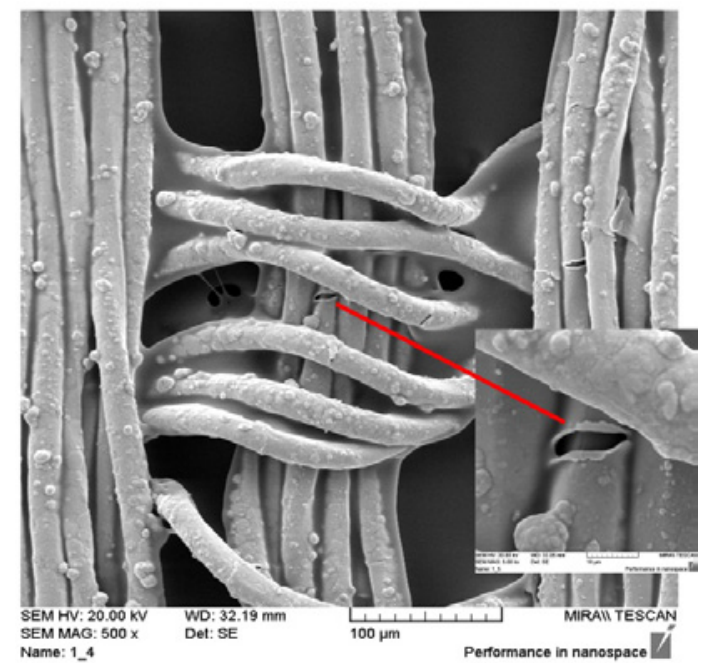

Figure 12: SEM image of the IF after the first dry cleaning cycle

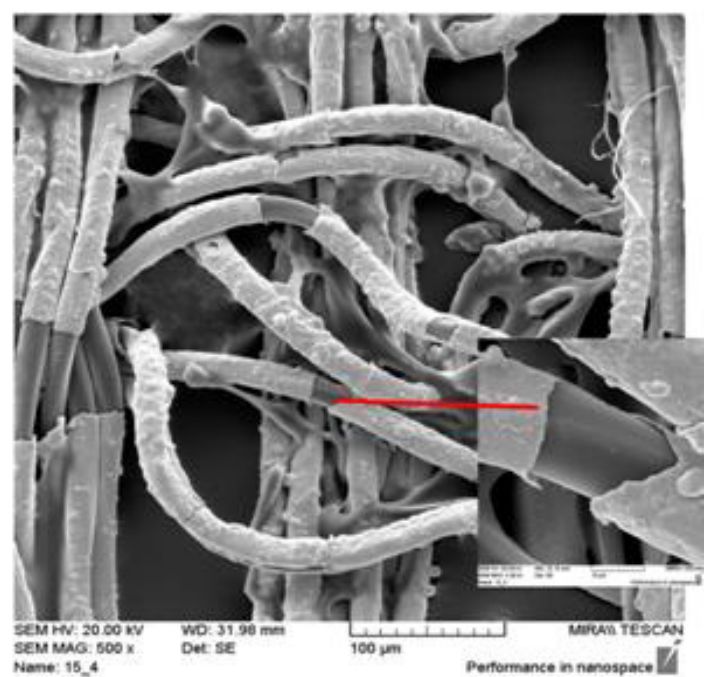

Figure 13. SEM image of IF after ten dry cleaning cycles

Despite slight processing in dry cleaning procedure, it is evident an initial degradation of copper coatings, which caused the SE decline. 
Dry cleaning procedure performed was very gentle, meaning that mechanical agitation was minor. Figure 12 presents SEM image of the IF surface after the first dry cleaning cycle.

Figure 13 presents SEM image of the IF after the tenth dry cleaning cycle where the surface damages are visible due to cracks in the copper coating. This resulted in great EM radiation passage and minimized SE values. The SEM image confirms complete loss of the IF shielding after ten consecutive cycles.

\section{CONCLUSIONS}

The interlining fabric made up of PA yarn coated with copper was evaluated for its protective properties against EM radiation at the frequencies of $0.9,1.8,2.1$ and $2.4 \mathrm{GHz}$, before and after the $1^{\text {st }}, 3^{\text {rd }}, 5^{\text {th }}, 7^{\text {th }}$ and $10^{\text {th }}$ dry cleaning cycle.

The best IF shielding properties are recorded at the frequency of $2.1 \mathrm{GHz}$ on the fabric reverse side and $1.8 \mathrm{GHz}$ on the fabric face before dry cleaning treatment. The SE decreases on both fabric sides in the range of 0.9 to $2.4 \mathrm{GHz}$ with the increasing number of dry cleaning cycles. Better shielding properties are noticed on the fabric reverse side. The seventh cycles dry cleaning impacts the fabric SE significantly on both the fabric face and reverse side.

The results obtained have shown that the interlining fabric has good protective properties against EM radiation, but after dry cleaning treatment, reduction is observed. SEM micrographs of the interlining surface confirmed that SE declined due to degradation and firing of the copper layers during the process of dry cleaning.

\section{References}

1. Ammari M., et al. (2008) Exposure to GSM $900 \mathrm{MHz}$ Electromagnetic Fields Affects Cerebral Cytochrome Coxidase Activity, Toxicology, 250, 70-74

2. Sage C., Carpenter D.O., (2012), A Rationale for Biologically-based Exposure Standards for Low-Intensity Electromagnetic Radiation, Biolnitiative, December 31st, USA

3. Saini B.S., Pandey A., (2013) Effect of Mobile Phone and BTS Radiation on Heart Rate Variability, International Journal of Research in Engineering and Technology, (2) 4, 662-666, ISSN 2319 - 1163

4. Rau M., et al. (2011) The Study of the Electromagnetic Shielding Properties of a Textile Material with Amorphous Microwire, Advances in Electrical and Computer Engineering, 11 (1), 17-22.

5. Shangcheng $X$., et al. (2010), Exposure to $1800 \mathrm{MHz}$ Radiofrequency Radiation Induces Oxidative Damage to Mitochondrial DNA in Primary Cultured Neurons, Brain Research 1311, 189-196

6. Duran D., Kadoglu H., (2012), A Research on Electromagnetic Shielding with Copper Core Yarns, Tekstil ve Konfeksiyon, 4, 354-359

7. Brzezinski S., et al. (2009), Textile Multi-layer Systems for Protection Against Electromagnetic Radiation, Fibres \& Textiles in Eastern Europe, 17 (73), 66-71
8. Koprowska J., Pietranik M., Stawski W., (2004), New Type of Textiles with Shielding Properties, Fibres \& Textiles in Eastern Europe, 12 (47), 39-42

9. Grabowska K. E. Marciniak K, Ciesielska-Wróbel I. L.(2011), The analysis of attenuation of electromagnetic field by woven structures based on hybrid fancy yarns, Textile Research Journal, 81(15) 1578-1593

10. Cheng, K. B.; Lee, M. L.; Ueng, T. H. (2001), Electromagnetic Shielding Effectiveness of Stainless Steel/Polyester Woven Fabrics, Textile Research Journal, 71 (1), 42-49;

11. Ciesielska-Wrobel I, Grabowska, K (2012) Estimation of the EMR Shielding Effectiveness of Knit Structures, Fibres \& Textiles in Eastern Europe, 20, 2 (91), 53-60

12. Roh, J-S et al (2008), Electromagnetic Shielding Effectiveness of Multifunctional Metal Composite Fabrics, Textile Research Journal, 78 (9), 825-835

13. ÖZEN M.S., et al. (2012), An Investigation of Electromagnetic Wave Absorption Potential of Woven Fabrics with Stainless Steel Wire, RMUTP International Conference Textiles \& Fashion 2012, July 3-4, Bangkok, Thailand

14. Ozdemir H., Ozkurt A., (2013), The Effects of Fabric Structural Parameters on the Electromagnetic Shielding Effectiveness, Tekstil 62, 134-144

15. Çeken F., et al. (2011), The Electromagnetic Shielding Properties of Copper and Stainless Steel Knitted Fabrics, Tekstil, 60, 295-354

16. Ceken F., et al. (2012), Electromagnetic Shielding Properties of Plain Knitted Fabrics Containing Conductive Yarns, Journal of Engineered Fibers and Fabrics, 7 (4), 81 87

17. Sonehara M., et al. (2009), Development of an Electromagnetic Wave Shielding Textile by Electroless $\mathrm{Ni}$ Based Alloy Plating, IEEE Transactions on Magnetics, Vol. 45, 10, 4173-4175

18. Duran D., Kadoglu H., (2010), Protection Against Electromagnetic Waves with Textiles, (Ed. Dragčević Z.), 5th International Textile, Clothing \& Design Conference - Magic World of Textiles, October 03rd to 06th 2010, Dubrovnik, Croatia, 231-234, ISSN 18477275

19. Das A., et al. (2009), Effect of Various Parameters on Electromagnetic Shielding Effectivenes of Textile Fabrics, Indian Journal of Fibers \& Textile Research, 34, 144-148

20. Sonehara M., et al. Preparation and Characterization of Nanofiber Nonwoven Textile for Electromagnetic Wave Shielding, (2008), IEEE Transactions on Magnetics, 44 (11), 3107-3110

21. Malarić K., (2010), EMI Protection for Communication Systems, Boston, USA, Artech House, 685 Canton Street, Norwood, MA 02062, ISBN 13: 978-1-59693-313-2

22. IEEE STD 299 Standard Method for Measuring the Effectiveness of Electromagnetic Shielding Enclosures, 299, 2006

23. MIL-STD-285, Military Standard: Attenuation Measurements for Enclosures, Electromagnetic Shielding, 1956

24. ASTM D-4935-89 Standard Test Method for Measuring the Electromagnetic Shielding Effectiveness of Planar Materials, 1999 